\title{
The Variation in Plasma Cortisol Levels in Response to Anesthetic Induction with Etomidate or Ketamine in Children Undergoing Intracardiac Repair of Tetralogy of Fallot on Cardiopulmonary Bypass
}

\author{
Anil K. Pandey ${ }^{1}$, Sandeep Chauhan ${ }^{1}$, Neeti Makhija ${ }^{1}$, Usha Kiran ${ }^{1}$, Sumit Vasdev $^{1}$, Sachin Talwar ${ }^{2}$, \\ Ramakrishnan Lakshmy ${ }^{3}$ \\ ${ }^{1}$ Departments of Cardiac Anaesthesia, All India Institute of Medical Sciences, New Delhi, India \\ ${ }^{2}$ Departments of Cardiac Surgery, All India Institute of Medical Sciences, New Delhi, India \\ ${ }^{3}$ Departments of Cardiac Biochemistry, All India Institute of Medical Sciences, New Delhi, India \\ Email: anilpandey18@gmail.com
}

Received March 27, 2012; revised May 16, 2012; accepted May 28, 2012

\begin{abstract}
Objective: To compare the effect of a single induction dose of etomidate or ketamine on plasma cortisol levels in children with Tetralogy of Fallot (TOF) undergoing intra-cardiac repair on cardiopulmonary bypass (CPB). Design: A prospective randomized trial. Setting: Cardiac center of a tertiary care hospital. Participants: Thirty children with TOF undergoing intra-cardiac repair on CPB. Interventions: After random allocation of the children into two groups, the children either received etomidate $0.2 \mathrm{mg} / \mathrm{kg}$ or ketamine $2 \mathrm{mg} / \mathrm{kg}$ intravenously for anesthetic induction along with fentanyl $2 \mathrm{mcg} / \mathrm{kg}$ and midazolam $100 \mathrm{mcg} / \mathrm{kg}$. Endotracheal intubation was accomplished with rocuronium bromide in the dose of $1 \mathrm{mg} / \mathrm{kg}$. Anesthesia was maintained with sevoflurane in air-oxygen, titrated to response and supplemental vecuronium bromide for muscle relaxation, fentanyl chloride for pain relief. Serum cortisol was measured on three occasions, at preinduction, at the end of surgery and at 24 hours postoperatively. Measurements and Main Results: Baseline plasma cortisol (Normal $5-25 \mathrm{mcg} / \mathrm{dl})$ in the etomidate group $(19.91 \pm 3.51 \mathrm{mcg} / \mathrm{dl})$ decreased significantly at the end of surgery $(5.78 \pm 2.0 \mathrm{mcg} / \mathrm{dl})$ and rose to significantly higher than baseline values at 24 hours $(27.31 \pm 8.30$ $\mathrm{mcg} / \mathrm{dl})$. The baseline cortisol levels in the ketamine group $(20.91 \pm 3.19 \mathrm{mcg} / \mathrm{dl})$ increased significantly at the end of surgery (44.02 $\pm 5.49 \mathrm{mcg} / \mathrm{dl})$ and remained significantly higher than baseline at $24 \mathrm{hours}(45.93 \pm 3.05 \mathrm{mcg} / \mathrm{dl})$. Plasma cortisol levels in the etomidate group at end of surgery, and at 24 hours post-operatively, were significantly lower than the ketamine group. Conclusions: This study shows that etomidate is a suitable and safe agent for suppression of the increase in serum cortisol associated with the use of CPB in children with TOF undergoing intra-cardiac repair.
\end{abstract}

Keywords: Serum Cortisol; Tetralogy of Fallot (TOF); Etomidate

\section{Introduction}

A severe stress response evoked by cardiopulmonary bypass is well described including an increase in plasma cortisol levels [1]. Studies confirm that reduction of the stress response in children undergoing cardiac surgery helps improve postoperative morbidity [2,3]. Etomidate is an intravenous, sedative-hypnotic induction agent with an excellent cardiovascular stability. There are some reports in the literature that suggest etomidate can induce adrenocortical suppression after single-dose or long-term use [4, 5], whereas others suggest that this inhibition is reversible in normal healthy subjects [6].

Studies on the effect of a single dose of etomidate on cortisol suppression in children with Tetralogy of Fallot
(TOF) are lacking. In this study, the suppressive effect of a single induction dose etomidate on cortisol secretion in children with TOF undergoing intra-cardiac repair on cardiopulmonary bypass (CPB) was evaluated.

\section{Materials and Methods}

30 children with TOF, aged between 12 to 26 months scheduled for intra-cardiac repair on CPB were included in the study after approval from institutional ethics committee. The children were pre-medicated with oral promethazine $0.5 \mathrm{mg} / \mathrm{kg} 1$ hour prior to surgery. The children were administered fentanyl $2 \mathrm{mcg} / \mathrm{kg}$ intravenously (iv) and midazolam $100 \mathrm{mcg} / \mathrm{kg}$ iv prior to induction of anesthesia with ketamine $2 \mathrm{mg} / \mathrm{kg}$ iv (Ketamine Group, $\mathrm{n}=$ 
15) or etomidate (B. Braun Melsungen AG, Germany) $0.2 \mathrm{mg} / \mathrm{kg}$ iv (Etomidate Group, $\mathrm{n}=15$ ). The etomidate preparation used was a preservative free emulsion. There was no pain on injection or myoclonus. The trachea was intubated following a single intravenous dose of rocuronium bromide, $1 \mathrm{mg} / \mathrm{kg}$. Anesthesia was maintained with sevoflurane in air-oxygen, and supplemental fentanyl, vecuronium and midazolam in both groups. Arterial and central venous cannulas, urinary catheter, esophageal and rectal temperature probes were inserted after the induction of anesthesia. Lactated ringers solution was infused and blood loss replaced with fresh frozen plasma or whole blood until the start of CPB, according to the cardiovascular status and and hematocrit status of the patient.

Antifibrinolytic in the form of epsilon amino caproic acid (EACA) in the dose of $100-125 \mathrm{mg} / \mathrm{kg}$ was used pre-CPB, on $\mathrm{CPB}$ and post $\mathrm{CPB}$.

During $\mathrm{CPB}$, mild hypothermia $\left(35^{\circ} \mathrm{C}\right)$ was used. The administration of sevoflurane was continued till the initiation of CPB. Pancuronium, $0.1 \mathrm{mg} / \mathrm{kg}$, midazolam 0.2 $\mathrm{mg} / \mathrm{kg}$ and fentanyl, $2-5 \mathrm{mcg} / \mathrm{kg}$ were administered into the reservoir of the pump. Cardiopulmonary bypass was performed using a membrane oxygenator with prime volumes of $35 \mathrm{~mL} / \mathrm{kg}$ (crystalloid solution and packed Red blood cells). The pump flow and hematocrit were maintained at $125-150 \mathrm{ml} / \mathrm{kg} / \mathrm{min}$ and $30 \%$ to $32 \%$, respectively. The patients were either first or second on a morning operating list to avoid any effects of diurnal variation of hormone concentrations. Blood samples for plasma cortisol were collected before induction of anesthesia, at the end of surgery and 24 hours postoperatively. The blood samples were placed in melting ice and centrifuged immediately, and the plasma was separated and stored frozen at minus $70^{\circ} \mathrm{C}$. Plasma cortisol was measured with commercially available radioimmunoassay kit, Tdx Cortisol (Abbott, IL). Normal value for serum cortisol was 5 to $25 \mathrm{mcg} / \mathrm{dl}$. Cortisol levels are presented as mean \pm standard deviation. Statistical analysis was performed by Mann-Whitney $U$ test between and within the groups; $\mathrm{p}<0.05$ was considered significant.

\section{Results}

The patient demographic variables and data pertaining to CPB are listed in Table 1. The two groups did not differ significantly with respect to age, weight, duration of cross clamping, and CPB times.

Mean values for plasma cortisol concentrations are presented in Tables $\mathbf{2}$ and $\mathbf{3}$. The baseline plasma cortisol values were similar in the two groups $(\mathrm{p}=0.422)$. Plasma cortisol levels decreased significantly at the end of surgery in the etomidate group $(p=0.000)$. The values at end of surgery were significantly lower than the values at 24 hours $(\mathrm{p}=0.000)$.
Table 1. Demographic profile, CPB time and aortic crossclamp time.

\begin{tabular}{ccc}
\hline & $\begin{array}{c}\text { Ketamine } \\
(\mathrm{n}=15)\end{array}$ & $\begin{array}{c}\text { Etomidate } \\
(\mathrm{n}=15)\end{array}$ \\
\hline Age (months) & $17.93 \pm 4.68$ & $18.86 \pm 3.81$ \\
Sex (M/F) & $9 / 6$ & $8 / 7$ \\
Weight (kg) & $10.3 \pm 2.77$ & $12.42 \pm 2.79$ \\
CPB time (min) & $64.35 \pm 5.06$ & $60.87 \pm 6.20$ \\
Aortic cross clamp time & $40.23 \pm 2.08$ & $41.35 \pm 2.63$ \\
\hline
\end{tabular}

Values are mean \pm standard deviation.

Table 2. Comparison of serum cortisol values between baseline and end of surgery.

\begin{tabular}{cccc}
\hline \multirow{2}{*}{ Group } & \multicolumn{3}{c}{ Serum Cortisol mcg/dL (Mean \pm SD) } \\
\cline { 2 - 4 } & Baseline & End of Surgery & $\mathrm{p}$ Value \\
\hline Etomidate $(\mathrm{n}=15)$ & $19.91 \pm 3.51$ & $5.78 \pm 2.00$ & 0.000 \\
Ketamine $(\mathrm{n}=15)$ & $20.91 \pm 3.19$ & $44.02 \pm 5.49$ & 0.000 \\
$\mathrm{p}$ Value & 0.422 & 0.000 & \\
\hline
\end{tabular}

Table 3. Comparison of serum cortisol values between baseline and 24 hours post surgery.

\begin{tabular}{cccc}
\hline \multirow{2}{*}{ Group } & \multicolumn{3}{c}{ Serum Cortisol mcg/dL (Mean \pm SD) } \\
\cline { 2 - 4 } & Baseline & 24 Hours post Surgery & $\mathrm{p}$ Value \\
\hline Etomidate $(\mathrm{n}=15)$ & $19.91 \pm 3.51$ & $27.31 \pm 8.30$ & 0.003 \\
Ketamine $(\mathrm{n}=15)$ & $20.91 \pm 3.19$ & $45.93 \pm 3.05$ & 0.000 \\
$\mathrm{p}$ Value & 0.422 & 0.000 & \\
\hline
\end{tabular}

In the ketamine group, plasma cortisol levels increased significantly at end of surgery and remained high at 24 hours post surgery $(p=0.000)$. Plasma cortisol levels of the etomidate group at the end of the operation and at the end of 24 hours post surgery, were significantly lower than the ketamine group $(\mathrm{p}=0.000)$.

\section{Discussion}

The results of this study show that plasma cortisol levels in the etomidate induction group decreased at the end of the operation, and 24 hours postoperatively as compared with the ketamine group.

Adult patients, who experienced increased hormonal and metabolic responses in response to CPB and surgery, had a greater incidence of postoperative complications $[3,7]$. There is better evidence that lessening the stress response in young children undergoing cardiac surgery is of benefit $[1,2]$. The response of newborns, in particular, to the stress of cardiac surgery is greater than that of adults [1,2]. Prevention of the glucocorticoid response to surgery during the perioperative period is considered a therapeutic goal by many anesthesiologists. 
Ketamine is usually the agent of choice for anesthetic induction in children with TOF due to the advantage of increased systemic vascular resistance on reduction of right to left shunt and maintenance of cardiovascular stability in these children.

Etomidate is theoretically an attractive choice for induction of anesthesia in children with congenital heart disease who cannot tolerate the hemodynamic effects of other induction agents. In comparative studies with other anesthetic drugs, etomidate is usually described as the drug with the least effect on hemodynamic variables [8]. Kay used etomidate to induce anesthesia in 198 children between 6 hours and 1 - 5 years of age and showed that it produces a rapid and safe sleep with minimal cardiovascular changes [9]. The authors used etomidate and ketamine, which are safe agents for cardiovascular surgery for anesthesia induction in these patients.

Etomidate induction of anesthesia suppresses the usual large increases in plasma cortisol levels associated with anesthesia and surgery $[4,10,11]$. These levels remain low till at least 4 hours after the onset of anesthesia [4, $10]$.

Etomidate usage for a prolonged duration directly affects adrenal function and inhibits cortisol synthesis [5, 12]. Consensus is lacking about the adrenocortical function suppression after a bolus dose of etomidate in adults in various studies. It was concluded by Sebel et al. [13] that there was no difference in cortisol levels between anesthetic inductions with thiopentone versus etomidate. Fragen et al. [13] on the other hand found that etomidate induction depressed the blood cortisol compared to induction with thiopentone.

It was shown by Wagner et al. [4] that etomidate inhibited the adrenocortical function for at least 4 hours after its administration for anesthesia induction in adults undergoing cardiac and vascular surgery.

Anesthesia induction with thiopentone was associated with an increase in plasma cortisol levels, which retuned to near normal values at twelve hours. On the contrary induction with etomidate does not cause any such increase [13].

On investigating effects of etomidate induction on the mother for caesarean section on the neonate, it was concluded that etomidate did cause a transient suppression of plasma cortisol concentrations in neonates [14].

Morel et al. studied the effects of a single bolus dose of etomidate on adult patients undergoing elective cardiac surgery. They concluded that etomidate blunts the hypothalamic-pituitary-adrenal axis response for more than 24 hours, but it was not associated with increased vasopressor requirements [15].

Madhur et al. have shown that etomidate and ketamine can be used safely in combination for short cardiac catheterization procedures, in pediatric patients with intra-car- diac shunts [16].

Our's is one of the few studies investigating the effects of etomidate on plasma cortisol concentrations in pediatric patients with a diagnosis of tetralogy of Fallot undergoing intra cardiac repair on CPB. Plasma cortisol values in the etomidate group were low at the end of operation, and 24 hours postoperatively. Plasma cortisol concentrations of the ketamine group were higher than the etomidate group at the end of operation, and increased beyond baseline values at 24 hours postoperatively. Plasma cortisol concentrations of the ketamine group were higher than the etomidate group at the end of operation, and 24 hours postoperatively. Plasma cortisol levels at the end of surgery in the etomidate group were just 1/8 of the ketamine group. The difference in the serum cortisol, postoperatively in the two groups narrowed at twenty-four hours when the serum cortisol levels in the etomidate group were half those in the ketamine group. This difference was caused by the corticosuppressive effect of etomidate. It may be noted that the values at the end of surgery, in the etomidate group were well with in the normal limits.

The average baseline values in the two groups are comparable. The timing of induction of anaesthesia in both groups was maintained between 0800 hrs to 0900 hrs to avoid any effects of diurnal variation of cortisol levels on the study. As an institutional protocol the pediatric patients are taken up as the first case in the morning. The cases not starting with in the given time period due to any reason were excluded from the study.

Based on this study it can be concluded that etomidate can be used as an anesthetic induction agent to decrease the rise in plasma cortisol levels associated with intracardiac repair of tetralogy of Fallot in children using cardiopulmonary bypass.

\section{REFERENCES}

[1] B. J. Hindman, S. L. Lillehaug and J. H. Tinker, "Cardiopulmonary Bypass and the Anesthesiologist,” In: J. A. Kaplan, Ed., Cardiac Anesthesia, Saunders, Phildelphia, 1993, pp. 919-950.

[2] K. J. S. Anand, D. Phil, D. D. Hansen, et al., "Hormonal-Metabolic Stress Responses in Neonates Undergoing Cardiac Surgery,” Anesthesiology, Vol. 73, No. 4, 1990, pp. 661-670. doi:10.1097/00000542-199010000-00012

[3] J. Helman, W. Browner, J. Li, et al., "Prognostic Importance of Preoperative Hypertension,” Anesthesiology, Vol. 75, No. 3, 1991, p. 110A. doi:10.1097/00000542-199109001-00110

[4] R. L. Wagner, P. F. White, P. B. Kan, et al., "Inhibition of Adrenal Steroidogenesis by the Anesthetic Etomidate," The New England Journal of Medicine, Vol. 310, No. 22, 1984, pp. 1415-1421. doi:10.1056/NEJM198405313102202 
[5] M. P. Mehta, J. B. Dillman, B. M. Sherman, et al., "Etomidate Anesthesia Inhibits the Cortisol Response to Surgical Stress,” Acta Anaesthesiologica Scandinavica, Vol. 29, No. 5, 1985, pp. 486-489. doi:10.1111/j.1399-6576.1985.tb02239.x

[6] D. J. R. Duthie, R. Fraser and W. S. Nimmo, "Effect of Induction of Anaesthesia with Etomidate on Corticosteroid Synthesis in Man,” British Journal of Anaesthesia, Vol. 57, No. 2, 1985, pp. 156-159. doi:10.1093/bja/57.2.156

[7] M. F. Roizen, G. H. Lampe, D. J. Beuefiel, et al., "Is Increased Operative Stress Associated with Worse Outcome?” Anesthesiology, Vol. 67, No. 3, 1987, p. A1. doi:10.1097/00000542-198709001-00001

[8] J. G. Reves and D. E. Berkowitz, "Pharmacology of Intravenous Anesthetic Drugs,” In: J. A. Kaplan, Ed., Cardiac Anesthesia, Saunders, Philadephia, 1993, pp. 512534.

[9] B. Kay, "A Clinical Assessment of the Use of Etomidate in Children,” British Journal of Anaesthesia, Vol. 48, No. 3, 1976, pp. 207-210. doi:10.1093/bja/48.3.207

[10] R. A. Moore, M. C. Allen, P. J. Wood, et al., "Perioperative Endocrine Effects of Etomidate," Anaesthesia, Vol. 40, No. 2, 1985, pp. 124-130. doi:10.1111/j.1365-2044.1985.tb10702.x

[11] J. W. Sear, M. C. Allen, M. Gales, et al., "Suppression by
Etomidate of Normal Cortisol Response to Anaesthesia and Surgery,” Lancet, Vol. 322, No. 8357, 1983, p. 1028. doi:10.1016/S0140-6736(83)91013-9

[12] C. J. Kenyon, J. Young, C. E. Gray, et al., "Inhibition by Etomidate of Steroidogenesis in Isolated Bovine Adrenal Cells," The Journal of Clinical Endocrinology \& Metabolism, Vol. 58, No. 5, 1984, pp. 947-949. doi:10.1210/jcem-58-5-947

[13] P. S. Sebel, C. Verghese, H. L. J. Makin, R. J. Fragen, C. A. Shanks and A. Molteni, "Effect on Plasma Cortisol Concentrations of a Single Induction Dose of Etomidate or Thiopentone,” Lancet, Vol. 322, No. 8350, 1983, pp. 625626. doi:10.1016/S0140-6736(83)90709-2

[14] T. A. Crozier, C. Flamm, C. P. Speer, et al., "Effects of Etomidate on the Adrenocortical and Metabolic Adaptation of the Neonate," British Journal of Anaesthesia, Vol. 70, No. 1, 1993, pp. 47-53. doi:10.1093/bja/70.1.47

[15] J. Morel, M. Salard, C. Castelain, et al., "Haemodynamic Consequences of Etomidate Administration in Elective Cardiac Surgery: A Randomized Double-Blinded Study," British Journal of Anaesthesia, Vol. 107, No. 4, 2011, pp. 503-509. doi:10.1093/bja/aer169

[16] M. Malik, V. Malik, S. Chauhan, et al., "Ketamine-Etomidate for Children Undergoing Cardiac Catheterization," Asian Cardiovascular \& Thoracic Annals, Vol. 19 No. 2, 2011, pp. 143-148. 